\title{
Facilities Management for African Urban Marketplace: Attitudinal Change to Waste as a Core Strategy
}

\author{
Adeni Abigo $^{1}$, Kassim Gidado ${ }^{2}$ and Paul Gilchrist ${ }^{3}$
}

\begin{abstract}
Facilities management (FM) entails enhancing performance of users in a set environment towards optimising organisational targets. It is about managing user behaviour and includes the desire to provide a pleasant experience for the users of the facility in order to improve their performance. The handling of solid waste in the African urban marketplace environment (MPE) is documented to be a significant problem that needs addressing. Furthermore, the attitudes of the market users have been found to exacerbate this problem. The aim of this research was to identify attitudinal change factors to be incorporated in waste management strategies for the MPE. Research indicates that the key FM component in this facility is the environmental management component particularly the effective management of solid waste. In addition, success or failure of this facility hinges on attitudinal actions of the stakeholders towards waste. Data was collected from observations of four African MPEs and a series of semi-structured interviews with stakeholders. Attitudinal change factors identified in this paper include: waste collection frequency and monitoring of the waste management practices. The study reveals that a deeper understanding of marketplace custom and everyday relationship to market space is essential for enhancing waste management practices in the MPE.
\end{abstract}

Keywords: african marketplace, attitudinal change, facilities management, municipal solid waste management.

\section{Introduction}

The practice of facilities management (FM) has evolved over the years and entails enhancing performance of users in a set environment thereby optimising organisational targets. It also involves managing user behaviour, provision of pleasant user experience with an aim to improve facilities performance. Thus, the provision of FM services is based on a common objective; to provide services that support organisations to achieve their primary objectives. In the management of facilities, there are no laid down guidelines as to how to provide FM services or what FM services are to be provided in organisations. According to Atkin and Brooks (2014), even organisations within the same sector would differ in their FM needs. Facilities managers are therefore expected to understand the core business of the organisation therein in order to develop a strategy that will enhance the operations of the organisation and at the same time provide a conducive environment for the users/occupants of the facility.

The marketplace is considered an important feature of daily life and the centre of the community in developing countries especially in Africa (Mukherjee and Kumar, 2007). According to Neil and Paul (2001), cities and marketplaces have sustained each other

$1 \quad$ Research Student, School of Environment and Technology, University of Brighton, Lewes Road Brighton, BN2 4GJ, Tel: +44 (0) 1273 642288, E-mail: A.Abigo@brighton.ac.uk.

2 Principal Lecturer, School of Environment and Technology, University of Brighton, Lewes Road Brighton, BN2 4GJ, Tel: +44 (0)1273 642394, E-mail: K.I.Gidado@brighton.ac.uk.

3 Senior Lecturer, School of Environment and Technology, University of Brighton, Lewes Road Brighton, BN2 4GJ, Tel: +44 (0)1273 643889, E-mail: P.M.Gilchrist@brighton.ac.uk. 
throughout history; the location, demand and social context is provided by cities for the marketplace while the marketplace provides sustenance, profit and cultural life to cities. Marketplaces epitomise a special type of urban facility because they allow all users the actual experience of the features of a public facility; central, shared and sociable (Unlu-Yucesoy, 2013).

In Africa, one of the fundamental focal points of economic and social life is the marketplace because most city dwellers buy a majority of their foodstuffs from the markets and it provides an opportunity for most government programmes such as immunisation programmes, family life education, political campaigns etc., aimed at educating and reaching out to the public to be conveyed via the marketplace (Hill, 1963, Wambugu, 1995). The African marketplace is a unique facility with deep cultural significance in the African society. People meet at the marketplace in Africa for various reasons apart from trade activities which include; settling of disputes, meeting friends and next of kin, catching up on the latest news, exchanging of ideas, learning, religious activities, traditional festivals, political activities and social gatherings (Nelson, 1998, Henrich, 2006). According to Ladipo et al. (1990), there is rarely an African who does not in one way or the other participate in market life. Owing to the cultural significance and influence of the MPE in the African setting, the MPE is perceived as a vehicle for addressing public health issues and a springboard in bringing about change outside the marketplace environment. However, one significant challenge faced in the management of African marketplaces, is the management of solid waste.

Municipal solid waste management (MSWM) is one of the most crucial health and environmental challenges facing the governance of African cities (Achankeng, 2003, Mwesigye et al., 2009). From the point of waste generation to the point of disposal, waste management is characterised by inefficiencies (Palczynski, 2009). Waste is usually not segregated and is dumped indiscriminately along streets and even rivers causing environmental pollution, blockade to drainage systems/culverts thereby resulting in environmental pollution. This poses a risk to public health and defaces the physical environment (Ayotamuno and Gobo, 2004, Ogbonna et al., 2007). Most often waste management processes (especially reuse and recycling) are carried out informally by scavengers who risk their health in order to secure a source of livelihood by sorting out materials (especially glass, plastic and metal) that can be reused based on market availability (UNEP, 2005). Waste management is thus an issue of great concern to African governments and all stakeholders.

The practice of MSWM is no different in MPEs as solid waste is dumped indiscriminately on the ground and in the drains as illustrated in Figure 1, contributing immensely to environmental degradation, the pollution of the physical environment and also poses a risk to public health (Olaseha et al., 2005, Adekunle, 2012).
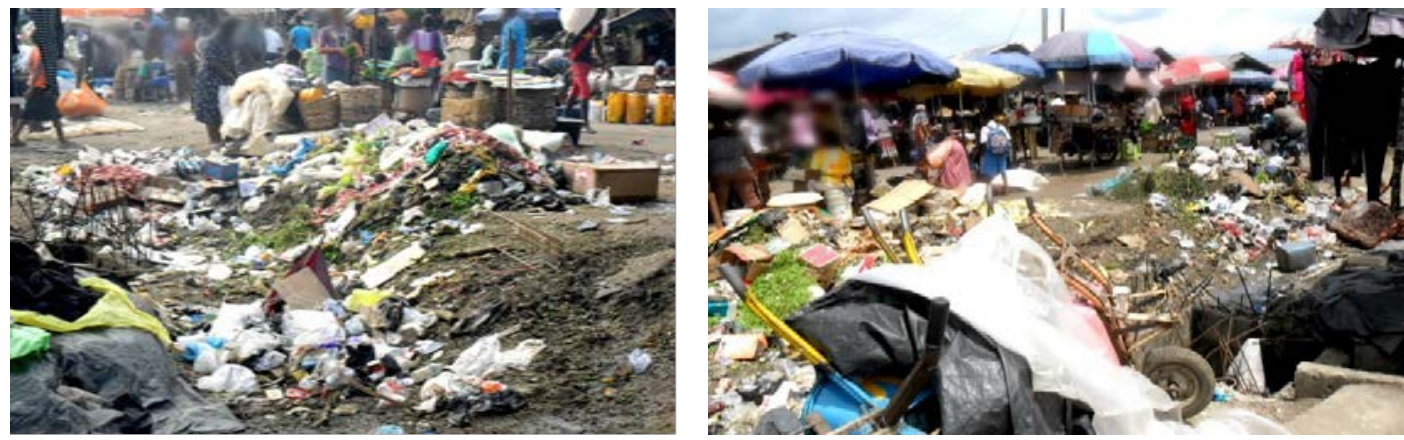

Figure 1. Indiscriminate dumping of Solid Waste at Marketplaces (Source: Author) 
Literature suggests among other factors that the attitudinal action, lack of awareness and low community participation of the users of this facility towards waste are major contributory factors to inadequate solid waste management (Olaseha et al., 2005, Adekunle, 2012, Agwu, 2012). Thus, in order to enhance the functioning of this facility and to make it a success, there is an urgent need to address the attitudinal actions of the users of this facility towards waste.

A WorldBank (2009) global report on the generation, treatment and disposal of livestock and slaughter waste in developing countries with the aim of developing global guidelines for potential bank interventions in the livestock market and slaughter sector established that, research on waste management in African marketplaces is an area that has been neglected despite the high risk to public health and environmental problems posed by waste in these facilities. This thus forms the relevance of this study and reveals the need to analyse the MPE as a facility in need of appropriate management especially with regards to the management of solid waste.

The practice of FM is dynamic; it entails proper consideration of the business environment and a clear understanding of the core business of the organisation in order to develop an appropriate FM strategy. The focus of this study is on the environmental management component of FM with particular focus on solid waste management as a key FM theme in this facility. The study intends to reveal what attitudinal change factors would enhance solid waste management practices in marketplaces. This will enable the facilities manager to address solid waste management concerns thereby enhancing the operational role of the facilities manager in providing a safe and pleasant environment to support the core business and at the same time address the risks posed by inappropriate handling of solid waste in this facility.

\section{Research Question}

The knowledge gap in this study resides in the management of markets; the managers of markets do not provide adequate or appropriate systems of handling and disposing solid waste. This means solid waste ends up on the ground, in drainages etc and this poses a risk to public health, causes environmental pollution and defaces the physical environment. In order to address the concerns of solid waste management in MPEs, this paper seeks to answer as to:

- Why we still have markets where waste is a problem?

- What are the factors that could enhance the attitudes of market users toward waste?

\section{Research Methodology and Context}

Although there is limited research in relation to the research phenomenon, the existing research on solid waste management in marketplaces has relied on qualitative, quantitative or mixed methods design.

The WorldBank (2009) global report which is most significant to this study utilised a qualitative research approach relying on observations as data collection technique. It was maintained that this method was most appropriate for the study as the research subject was under-studied and lacked data.

This study reports upon qualitative research findings obtained from four cases within a single case - Port Harcourt, Nigeria that met the study criteria; market frequency, location, and market type. The study criteria was limited to mixed markets that operate at least six days in a week and located in core areas of Port Harcourt. A combined philosophy of the pragmatist and the critical realist was adopted for this paper. The pragmatist upholds the philosophy that research can be undertaken by the use of whatever method or strategies that would result in valid research findings (Creswell, 2009) whereas the critical realist 
recognises the position of social structures and the importance of first understanding such social structures in order to understand a particular phenomenon (Bryman, 2012). The study described in this paper, provides a new perspective to analysing the marketplace (as a facility) away from the conventional approach of analysing markets; as many marketplace research have focus on the social and economic impacts of markets (Hill, 1966, Good, 1973, Jerome and Ogunkola, 2000, Watson and Studdert, 2006, Morales, 2011). The study also provides an understanding of the social structures that underpin the attitudes of the users of the MPE.

The study area Port Harcourt (Figure 2) is the third largest city in the southern part of Nigeria and is considered as one of Nigeria's most important industrial and commercial cities with an estimated population of 2,340,000 (Ayotamuno et al., 2010, Demographia, 2015). It is located in the Niger Delta region of Nigeria and the operational base for multinational oil and gas businesses. According to UN-HABITAT (2009), the finding and extraction of oil in the Niger Delta in 1950's led to rapid influx of migrants. The heavy concentration of human population as well as industrial and commercial activities, led to complex land use systems and the solid waste generated increased in volume and variety (Ayotamuno and Gobo, 2004).

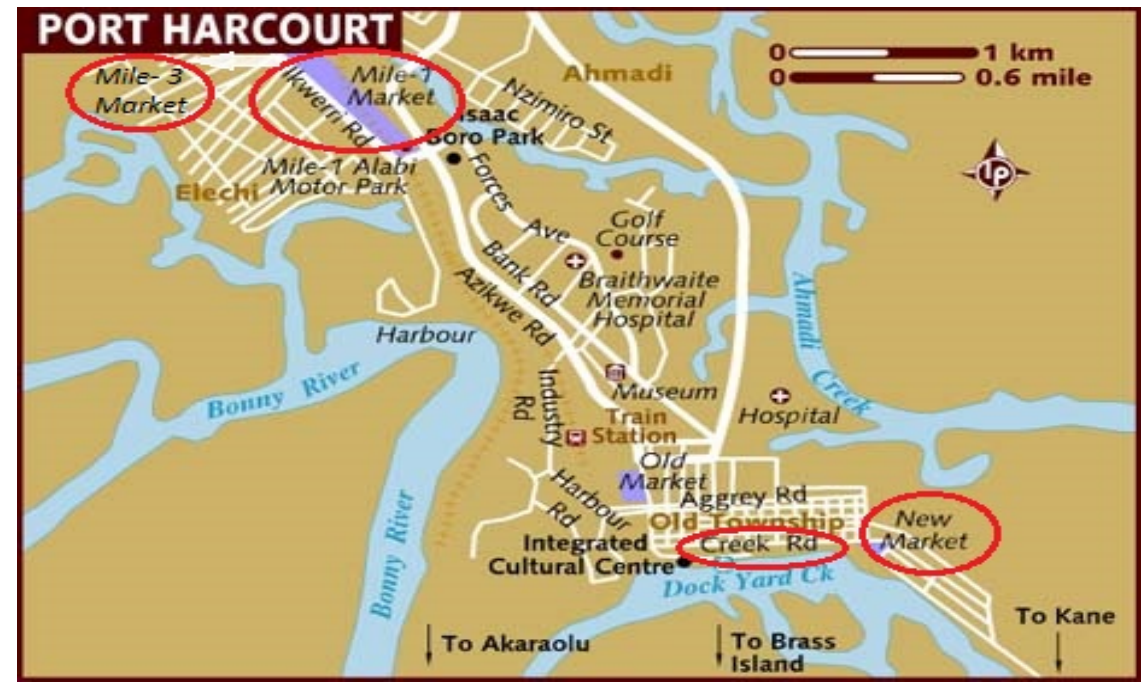

Figure 2. Map of Port Harcourt indicating Case Study Areas

Data obtained for this study was collated over a period of eight weeks. It included observations of four MPEs and semi-structured face-to-face interviews with key stakeholders, in order to provide an in-depth understanding of the dynamics of MPEs and current solid waste management practices within MPEs. The selected cases comprised of two old markets and two remodeled markets and for the purpose of this study will be referred to as; old market South and North and remodelled market South and North.

The data collection process began with preliminary enquiries from the Local Government Council so as to establish the number of urban markets and select cases that met the study criteria. The structure of urban market management and communication channel was also determined. The primary data collection began afterwards with observation, which was divided into two phases. Phase 1 was the fact-finding phase which entailed the collation of information such as; the physical settings and layout of the MPEs, MPE facilities and services and management operations. This enabled the mapping out of strategy and activities for the next phase. Phase 2 was the actual observation and a total of thirty six days was spent undertaking this phase. The aim of the observation was to gain insights into the settings and dynamics of the MPE and to determine current solid waste management practices. 
After data from the observations was collated, a series of semi-structured face-to-face interviews were conducted with various categories of MPE stakeholders established in the course of the study. Themes explored in the semi-structured interviews, for example, the provision of waste management facilities by the State Government were identified through critical literature review ((Adekunle, 2012). Additional themes considered in interviews such as waste disposal cultures and practices of stakeholders were developed from initial observations of interactions of individuals in MPE. Stakeholders were categorised into five groups: (a) buyers and visitors $(\mathrm{n}=12)$, (b) traders $(\mathrm{n}=15)$, (c) regulators, including market superintendents, chairmen of market management committee and associations, and State sanitation authority officers ( $n=7)$, (d) waste handlers and contractors $(n=3)$, and sensitisation groups, including health organisations, banks, and political parties $(n=6)$. A total of thirty nine (39) interviews were transcribed and useful for analysis. With the use of NVivo - a computer-assisted qualitative data analysis software, the interviews were further organised and analysed with the application of thematic coding, a qualitative analytical tool in order to identify themes, concepts and relationships within the data and also between the data and literature.

\section{Summary of Findings}

\section{Management of MPEs}

Markets in urban centres are built by the State Government after which its ownership is transferred to the Local Government Council (LGC). In the management of marketplaces, the LGC deploys its staff to marketplaces, headed by a member usually referred to as the "chairman". Among the duties of the market superintendents is the allocation of stalls/stores, record keeping, collection of revenue (this includes monthly store rentage, sanitation and security fee), provision of a conducive retail environment, and addressing complaints arising in the marketplace. The MPE also have a traders' association, which is headed by a chairman with members of the executive elected by the traders. The key responsibility of the traders' association is to oversee the welfare of the traders and also represent the traders in dealings with the LGC. There is also the market council, made of elderly and long standing traders who assist in decision making regarding market welfare.

\section{Description and Condition of MPEs}

\section{Old Markets}

The old markets are in poor condition as they are characterised by very old and shabby sheds - combination of lock-up stores and open sheds, congested space, uneven and muddy paths and external roads, open and filthy drainages, waste litters and fly dumping at various corners of the market. A selection of old markets is represented on Figure 3.
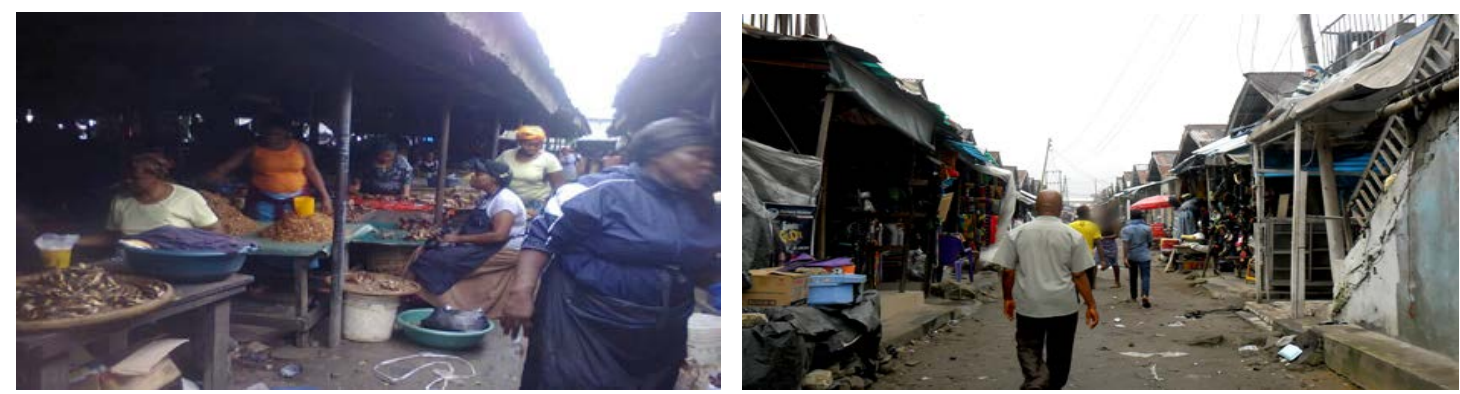

Figure 3. A Section of Old Market South and North Respectively. 
The majority of the stores are not connected to the national grid supplying electricity and there is no public mains of water supply or independent water supply - borehole. Traders that could afford it have generator plants for the supply of electricity, and traders who stay until dark - late evenings - rely on torchlights or bush lanterns ${ }^{1}$. The traders in the old markets rely on mai ruwa ${ }^{2}$ or pure water $^{3}$ for their daily water supply. There are no car parks for shoppers or deliveries and the markets are services with open drainage which eventually are dumpsites for waste.

\section{Remodelled Markets}

Generally, the remodelled markets are well organised, in good condition and offer a convenient environment. A selection of remodelled markets is represented on Figure 4.
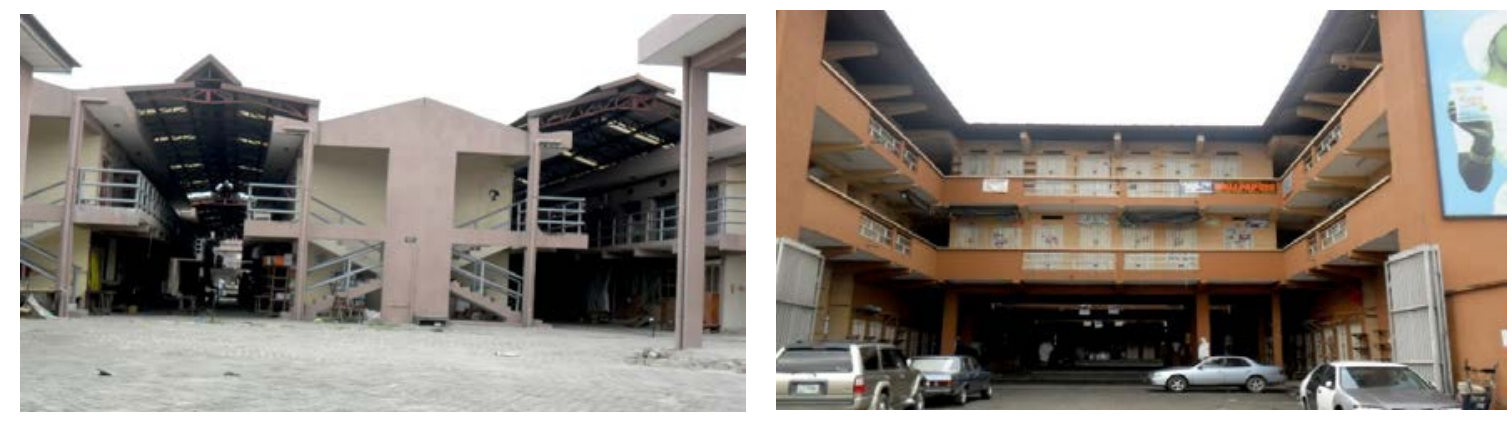

Figure 4. A Section of Remodelled Market South and North Respectively.

The remodelled markets are serviced with; toilets, water - internal borehole installed on premises, electricity from national grid, covered drains, car park, fire hose and extinguishers, banks, cafeteria and refuse dump areas.

\section{Solid Waste Management Practices in MPEs}

In Port Harcourt, the Rivers State Environmental Sanitation Authority (RSESA) is responsible for waste management, with the collection, transportation and disposal of waste contracted to private contractors. Data obtained from interviews with the contractors responsible for the collection of waste at MPEs reveal that, the approach to waste collection is either by truck placement or the evacuation of waste from authorised areas at 6:00pm in the evenings. However, findings from qualitative data sets reveal that a majority of the traders attend to their waste at the close of market (between 6:00 and 7:00pm) or most often before the start of trade activities the following morning (between 6:30 and 8:00am). This is as a result of the busy nature of markets; markets are busy and at the peak of transaction between the hours of 9:00am till 5:00pm daily. It is thus market custom that waste is disposed of most often in the mornings rather than evenings. This has an implication on solid waste management practices in marketplaces as this custom is contrary to the stipulated waste collection times and has a resulting effect on solid waste management practices in MPEs.

Extracts from interviews reveal that, the customary practices of waste disposal linked to the convenience and operation of market trading are significant factors responsible for the act of indiscriminate disposal and the poor handling of waste by market users. Studies by Ogwueleka (2009), Regassa et al. (2011) and Ayuba et al. (2013) also established that these

\footnotetext{
${ }^{1}$ Lanterns with exposed flames fuelled with kerosene - paraffin.

${ }^{2}$ People who move around with water for sale mostly in 20 litres jerry cans transported in hand pushed trucks.

${ }^{3}$ Sachet water which is usually 500 millilitres per sachet.
} 
factors are among key factors responsible for inefficient solid waste management practices in African cities.

Communication and consultation between waste contractors and market users are also key contributory factors to the problem of solid waste pollution in MPEs. Discussions with waste contractors reveal that the market users are not duly consulted before decisions are made about waste collection services. This presents a classic problem of implementation. The lack of communication and consultation between the stakeholders reveals proper consideration is not taken into account as to understanding the factors that underpin the attitudes of the market users. Extracts from interviews also suggests the use of discretionary power on the part of the waste contractors, as decisions are based on the perception of the waste contractor as to what is "right" for effective waste management practices. This reveals the problematic use of top-to-bottom approach in the management of waste in MPEs and confirms the findings of Palczynski (2009) that the non-involvement of stakeholders during the decision making and throughout the waste management process is an important element lacking in African societies.

Further investigation and discussions revealed the practice of re-use and recycling by traders within marketplaces. Materials such as cartons, polythene, shells of seafood, remnant from dried seafood, glass, plastic buckets and bottles are the common materials re-used or recycled in markets. However, extracts from interviews revealed that the traders do not have knowledge of these elements of waste management neither do they understand the implication of this practice. Rather, the practice is based on economic benefits and it aids their trade activities as materials such as cartons can be reused to display or package goods purchased by buyers.

\section{Factors that could Enhance Solid Waste Management Practices in MPEs}

Findings from qualitative data sets reveals a total of ten (10) factors that could enhance solid waste management practices of the market users. It is anticipated that the incorporation of these factors in the waste management strategy for MPEs would shift the paradigm from "poor" to "good" attitudes towards waste in the use of this facility. A summary of the factors (in no particular order) established from findings of this study is represented on Figure 5.

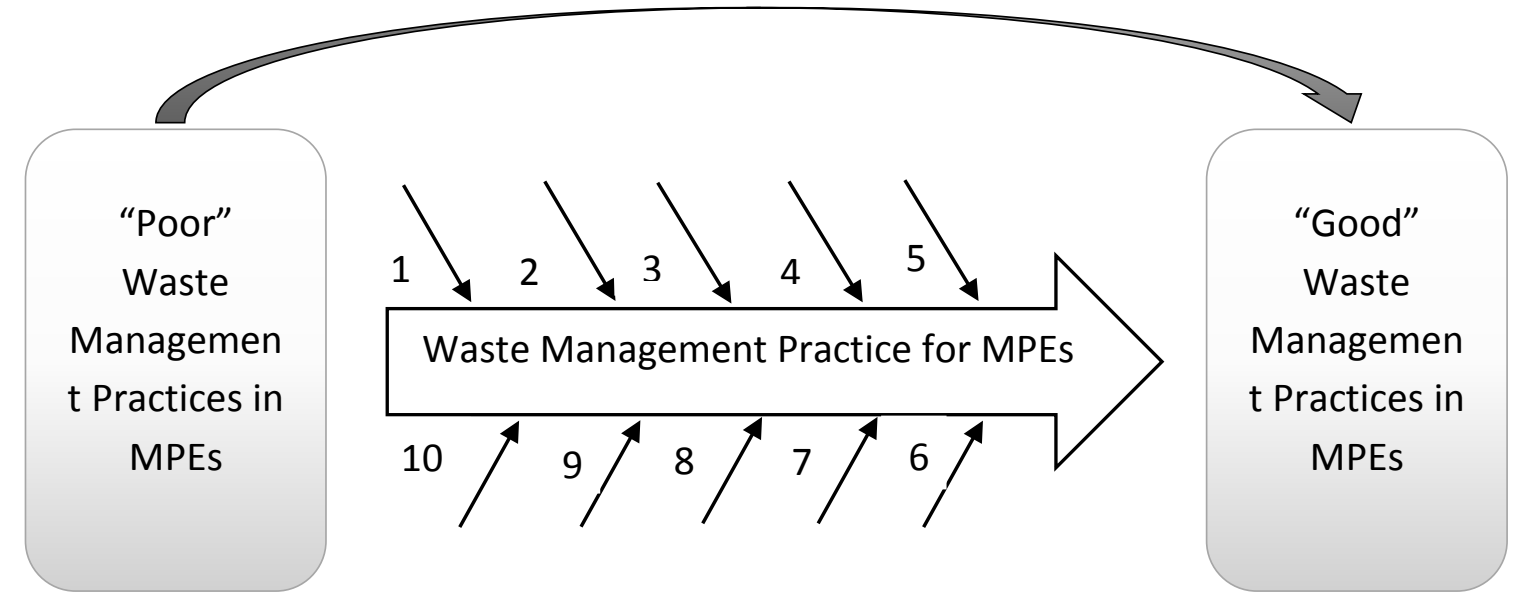

Figure 5. Summary of Factors that could enhance Solid Waste Management Practices in MPEs

1 - Appropriate market infrastructure: The stakeholders were of the opinion that the provision of closed drainage as opposed to open drains, "effective" bins within stores and at 
strategic locations within the MPE for public use, and the remodelling of the old markets were important factors that would enhance waste management practices in marketplaces. Effective in the context of the stakeholders, refers to the use of appropriate waste storage materials (preferably storage with lid) and putting the storage to appropriate use.

2 - Sensitisation and reorientation of market users regarding waste: A large population of market users especially the traders, lack knowledge regarding the implication of poor waste management practices. This factor was also established in studies by Ezeah and Roberts (2012) and Abila and Kantola (2013) as significant factors to addressing poor waste management practices in Nigeria.

3 - Improved waste collection times: Timely collection of waste here refers not just to the daily evacuation of waste in the evenings as is supposedly agreed between the Government and the waste contractors, but timely collection of waste here questions the appropriate time to evacuate waste from markets. Qualitative data sets established that the nature of marketplaces is such that the traders prefer to sweep, tidy up and dispose waste in the mornings before displaying their goods. This is contrary to waste collection times stipulated by the contractors. There is therefore a need for proper consultation and communication between the stakeholders (which is lacking) in order to determine appropriate collection times.

4 - Frequency in waste collection: Data sets established that frequency in terms of collection of waste at MPEs would entail collecting waste at least twice daily - mornings and evenings as opposed to just evenings.

5 - Daily Clean up and Market Sanitation: The stakeholders are of the opinion that if every trader cleans up in the morning before displaying their goods and also carry out the weekly market sanitation it would aid solid waste management practices. This reveals the expectations of everyday market life and to an extent reveals the market custom of cleaning up and disposing waste in the morning.

6 - Monitoring and Supervision: Again, the market users are of the opinion that monitoring and supervising waste management practices such as ensuring every store has an "effective" waste bin and supervising the disposal of waste so as to discourage fly dumping would enhance waste management practices in marketplaces.

7 - Imposition of Fines: Findings from qualitative data sets reveals that there already exist penalties for indiscriminate dumping. However, evidence from observations reveals an effective system and thus raises questions as to the effectiveness of the monitoring and supervision of waste management practices by market regulators.

8 - Employment of Market Cleaners: The key issue here is the expectations of the traders based on the fee paid for sanitation. Findings from interviews reveal that monies paid as sanitation fee are not appropriately accounted for by the Local Government Council. Thus, the lackadaisical attitude of the traders towards waste could be attributed to a tacit understanding on the part of the traders regarding responsibilities as a result of the sum paid for sanitation purposes.

9 - Provision of Signage: Findings from observations and interviews reveal that the lack of signage for directions is a significant factor that would enhance waste management practices in MPEs. 
10 - Provision of Waste Management Office (Waste Experts) within Marketplaces: Findings from qualitative data sets reveals the need for personnel with waste management expertise within marketplaces. Findings also suggest that the market regulators do not necessarily have the expertise to deal with the current waste management concerns.

\section{Conclusion}

This paper has established market custom towards waste as a significant underlying factor underpinning the attitudes of the market users towards solid waste management. It reveals that market customs and operations are not duly considered in the development of waste management strategies and this is contrary to FM approach in the management of facilities. FM approach provides that in order to develop appropriate strategies, the facilities manager requires a clear understanding of the core business, and the culture and environment in which the business exist. Thus, the current approach to solid waste management practices in MPEs indicates a need for adequate consultation and communication with market stakeholders and an in-depth understanding of market custom and operations relating to both market traders and market regulators. The findings also implies there is a need to review the current financial commitments regarding solid waste management in MPEs as the introduction of these new measures will no doubt have financial implication on solid waste management practices in MPEs.

In order to address the attitudes of the market users toward waste, this study has established 10 factors that should be considered in the management of solid waste in MPEs. Furtherance to this study is the determination of the contextual relationship between the factors established and the relative importance of each factor. This will inform the facilities manager on the factors to be prioritised in the management of solid waste in MPEs.

\section{References}

Abila, B. \& Kantola, J. 2013. Municipal Solid Waste Management Problems in Nigeria:

Evolving Knowledge Management Solution. World Academy of Science, Engineering and Technology, 78292-297.

Achankeng, E. Globalisation, Urbanisation and Municipal Solid Waste Management in Africa. Annual African Studies Association of Australasia and the Pacific Conference, , 1-3 October 2003 Adelaide, Australia.

Adekunle, B. F. 2012. Management of Traditional Markets in Ibadan, Nigeria: A Focus on Ojo'Ba and Oje Markets. Available: http://www.regionalstudies.org/uploads/BALOGUN_Femi_Adekunle.pdf [Accessed 11 October].

Agwu, M. 2012. Issues and Challenges of Solid Waste Management Practices in PortHarcourt City, Nigeria- a behavioural perspective. American Journal of Social and Management Sciences, 3(2) 83-92.

Atkin, B. \& Brooks, A. 2014. Total facility management, Chichester, Wiley-Blackwell.

Ayotamuno, A., Gobo, A. E. \& Owei, O. B. 2010. The impact of land use conversion on a residential district in Port Harcourt, Nigeria. Environment and Urbanization, 22(1) 259-265.

Ayotamuno, J. M. \& Gobo, A. E. 2004. Municipal solid waste management in Port Harcourt, Nigeria: Obstacles and prospects. Management of Environmental Quality: An International Journal, 15(4) 389-398.

Ayuba, K. A., Manaf, L. A., Sabrina, A. H. \& Sulaiman Wan Nur, A. 2013. Current Status of Municipal Solid Waste Management Practise in FCT Abuja. Research Journal of Environmental and Earth Sciences, 5295-304.

Bryman, A. 2012. Social research methods, Oxford, Oxford University Press. 
Creswell, J. W. 2009. Research design: qualitative, quantitative, and mixed methods approaches, London; Los Angeles, SAGE.

Demographia. 2015. Demographia World Urban Areas: 11th Annual Edition [Online]. Belleville, Illinois USA: Demographia. Available: www.demographia.com/dbworldua.pdf [Accessed 12 January 2015].

Ezeah, C. \& Roberts, C. L. 2012. Analysis of barriers and success factors affecting the adoption of sustainable management of municipal solid waste in Nigeria. J Environ Manage, 1039-14.

Good, C. M. 1973. Markets in Africa : a Review of Research Themes and the Question of Market Origins. Cahiers d'études africaines, 13(52) 769-780.

Henrich, J. 2006. Africa: Fun Projects for World History. Culver City: Social Studies School Service

Hill, P. 1963. Markets in Africa. Journal of modern African studies 1(4) 441-453.

Hill, P. 1966. Notes on Traditional Market Authority and Market Periodicity in West Africa. The Journal of African History, 7(2) 295-311.

Jerome, A. \& Ogunkola, O. 2000. Characteristics and Behaviour of African Commodity/Product Markets and Market Institutions and Their Consequences for Economic Growth. Explaining African Economic Growth Performance Conference Series. Center for International Development, Harvard.

Ladipo, O. A., Mcnamara, R., Delano, G. E., Weiss, E. \& Otolorin, E. O. 1990. Family Planning in Traditional Markets in Nigeria. Studies in family planning, 21(6) 311-321.

Morales, A. 2011. Marketplaces: Prospects for Social, Economic, and Political Development. Journal of Planning Literature, 26(1) 3-17.

Mukherjee, S. N. \& Kumar, S. 2007. Leachate from market refuse and biomethanation study. Environ Monit Assess, 135(1-3) 49-53.

Mwesigye, P., Mbogoma, J., Nyakang’o, J., Idan, I. A., Kapindula, D., Hassan, S. \& Berkel, R. V. 2009. Integrated Assessment of Present Status of Environmentally-Sound Management of Wastes in Africa [Online]. Addis Ababa, Ethiopia: UNITED NATIONS ECONOMIC AND SOCIAL COUNCIL. Available: http://www.uneca.org/csd/csd6/AfricanReviewReportonWasteManagementMainReport.pdf. [Accessed 2 December 2012].

Neil, J. S. \& Paul, B. B. (eds.) 2001. International Encyclopaedia of the Social and Behavioral Sciences, Oxford: Pergamon.

Nelson, M. 1998. Africa: It's Not a Country [Online]. Available: http://teacherlink.ed.usu.edu/tlresources/units/byrnes-africa/aindex.htm [Accessed 16 November 2012].

Ogbonna, D. N., Amangabara, G. T. \& Ekere, T. O. 2007. Urban solid waste generation in Port Harcourt metropolis and its implications for waste management. Management of Environmental Quality: An International Journal, 18(1) 71-88.

Ogwueleka, T. C. 2009. Municipal Solid Waste Characteristics And Management In Nigeria. IRANIAN JOURNAL OF ENVIRONMENTAL HEALTH SCIENCE \& ENGINEERING, 6(3) 173-180.

Olaseha, I. O., Sridhar, M. K. C. \& Oyewo, O. A. 2005. Developing Sustainable Market Waste Management through the Joint Efforts of Technocrats and Traders: A Case Study from Ibadan, Nigeria. International Journal of Health Promotion \& Education, 43(2) 1-9.

Palczynski, R. J. 2009. Study On Solid Waste Management Options for Africa, African Development Bank, Côte d’Ivoire. 
Regassa, N., Sundaraa, R. D. \& Seboka, B. B. 2011. Challenges and opportunities in municipal solid waste management: the case of Addis Ababa city, Central Ethiopia. Journal of human ecology, 33(3) 179-190.

Un-Habitat. 2009. Evictions and Demolitions in Port Harcourt: Report of Fact-Finding Mission to Port Harcourt City, Federal Republic of Nigeria [Online]. Available: http://www.unhabitat.org/downloads/docs/10010_1_593998.pdf [Accessed 20 December 2012].

UNEP. 2005. Solid Waste Management [Online]. United Nations Environmental Programme. Available:

http://www.unep.org/ietc/InformationResources/Publications/SolidWasteManagement Publication/tabid/79356/Default.aspx [Accessed 3 November 2012].

Unlu-Yucesoy, E. 2013. Constructing the Marketplace: A Socio-Spatial Analysis of Past Marketplaces of Istanbul. Built Environment, 39(2) 190-202.

Wambugu, S. K. 1995. A Spatio-Temporal Analysis of Periodic Markets in Nyeri District, Kenya. Eastern and Southern Africa Geographical Journal, 6(1) 60-73.

Watson, S. \& Studdert, D. 2006. Markets as sites for social interaction: spaces of diversity. Worldbank. 2009. Global Study of Livestock Markets, Slaughterhouses and Related Waste Management Systems [Online]. World Bank. Available: http://siteresources.worldbank.org/INTUSWM/Resources/4636175264154387/CointreauSWMStudyFinalReportFeb2009.pdf [Accessed 22 November 2012]. 